Photo-sensitive Ge nanocrystal based films controlled by substrate deposition temperature

This content has been downloaded from IOPscience. Please scroll down to see the full text.

Download details:

IP Address: 109.171.137.210

This content was downloaded on 01/08/2017 at 09:11

Manuscript version: Accepted Manuscript

Stavarache et al

To cite this article before publication: Stavarache et al, 2017, Semicond. Sci. Technol., at press: https://doi.org/10.1088/1361-6641/aa8154

This Accepted Manuscript is: ( 2017 IOP Publishing Ltd

During the embargo period (the 12 month period from the publication of the Version of Record of this article), the Accepted Manuscript is fully protected by copyright and cannot be reused or reposted elsewhere.

As the Version of Record of this article is going to be / has been published on a subscription basis, this Accepted Manuscript is available for reuse under a CC BY-NC-ND 3.0 licence after the 12 month embargo period.

After the embargo period, everyone is permitted to copy and redistribute this article for non-commercial purposes only, provided that they adhere to all the terms of the licence https://creativecommons.org/licences/by-nc-nd/3.0

Although reasonable endeavours have been taken to obtain all necessary permissions from third parties to include their copyrighted content within this article, their full citation and copyright line may not be present in this Accepted Manuscript version. Before using any content from this article, please refer to the Version of Record on IOPscience once published for full citation and copyright details, as permission will likely be required. All third party content is fully copyright protected, unless specifically stated otherwise in the figure caption in the Version of Record.

When available, you can view the Version of Record for this article at: http://iopscience.iop.org/article/10.1088/1361-6641/aa8154 


\title{
Photo-sensitive Ge nanocrystal based films controlled by substrate deposition temperature
}

\section{Ionel Stavarache*}

National Institute of Materials Physics, 405A Atomistilor Street, 077125 Magurele, Ilfov, Romania

E-mail: stavarache@infim.ro

\section{Valentin Adrian Maraloiu}

National Institute of Materials Physics, 405A Atomistilor Street, 077125 Magurele, Ilfov, Romania

E-mail: maraloiu@infim.ro

\section{Catalin Negrila}

National Institute of Materials Physics, 405A Atomistilor Street, 077125 Magurele, Ilfov, Romania

E-mail: catalin.negrila@infim.ro

\section{Petronela Prepelita}

National Institute for Laser, Plasma and Radiation Physics, 409 Atomistilor Street, 077125 Magurele, Ilfov, Romania

E-mail: garoi.petronela@inflpr.ro

\section{Ion Gruia}

University of Bucharest, Faculty of Physics, 405 Atomistilor Street, 077125 Magurele, Romąnia

E-mail: ion.gruia@yahoo.com

\section{Gheorghe Iordache}

KAUST - King Abdullah University of Science and Technology, Nanofabrication Core Lab, Al Khawarizmi Building 1 East, Level 3, Office 3417, Thuwal 23955-6900, Saudi Arabia

E-mail: gheorghe.iordache@kaust.edu.sa

\begin{abstract}
Lowering the temperature of crystallization by deposition of thin films on a heated substrate represents the easiest way to find new means to develop and improve new working devices based on nanocrystals embedded in thin films. The improvements are strongly related with the increasing of operation speed, substantially decreasing the energy consumption and reducing unit fabrication costs of the respective semiconductor
\end{abstract}


Photo-sensitive Ge nanocrystal based films controlled by substrate deposition temperature2

devices. This approach avoids major problems, such as those related to diffusion or difficulties in controlling nanocrystallites size, which appear during thermal treatments at high temperatures after deposition. It is reported here a significant progress given by structuring Ge nanocrystals (Ge-NCs) embedded in silicon dioxide $\left(\mathrm{SiO}_{2}\right)$ thin films by heating the substrate at $400{ }^{\circ} \mathrm{C}$ during co-deposition of $\mathrm{Ge}$ and $\mathrm{SiO}_{2}$ by magnetron sputtering. As a proof-of-concept, a Si/Ge-NCs: $\mathrm{SiO}_{2}$ photo-sensitive structure was fabricated thereof and characterized. The structure shows superior performance on broad operation bandwidth from visible to near-infrared, as strong rectification properties in dark, significant current rise in the inversion mode when illuminated, high responsivity, high photo-detectivity of $10^{14}$ Jones, quick response and significant conversion efficiency with peak value reaching $850 \%$ at $-1 \mathrm{~V}$ and about $1000 \mathrm{~nm}$. This simple preparation approach brings an important contribution to the effort of structuring Ge nanocrystallites in $\mathrm{SiO}_{2}$ thin films at a lower temperature for the purpose of using these materials for devices in optoelectronics, solar cells and electronics on flexible substrates.

Keywords: germanium nanocrystallites, electrical properties, photocurrent, responsivity, response time

Submitted to: Semiconductor Science and Technology

\section{Introduction}

In the past decades, nanostructured materials have been the focus of many research groups due to their improyed structural, optical and electrical properties, appropriate for various practical applications. Quantum confinement effect $(Q C E)$ is more powerful in bulk Ge compared to Si because of Ge greater excitonic Bohr radius (approximately $24 \mathrm{~nm}$ in the case of Ge and about $5 \mathrm{~nm}$ for $\mathrm{Si}$ )[1, 2]. Also, compared to Si, Ge has higher lattice parameter, carrier mobility and smaller energy gap, thermal conductivity or effective mass of the carriers[3]. Ge lower melting temperature of $938.3^{\circ} \mathrm{C}$ (compared to $1414{ }^{\circ} \mathrm{C}$ for $\mathrm{Si}$ ) and its compatibility with well-developed $\mathrm{Si}$ technology represent other major advantages that allow obtaining Ge-NCs at a lower temperature. All the above-mentioned advantages suggest that it would be much simpler to shift the electronic structure near the band gap of Ge[4, 5]. Controlling the morphology and Ge high diffusivity (that appear at high annealing temperatures) of nanocrystallites would facilitate advances in understanding their quantum confinement behavior and an easier evaluation of their performances for the potential inclusion in new devices[6, 7]. Nanostructured Ge embedded in $\mathrm{SiO}_{2}$ thin layer has a significant absorption coefficient because of localized states at the $\mathrm{Ge} / \mathrm{SiO}_{2}$ interface and higher optoelectronic conversion efficiency[8]. Devices using such functionalized thin layers are photo-sensitive and they show high responsivity within a broad wavelength range from ultraviolet (UV), through visible (VIS) to near-infrared (NIR) making them materials of choice for many technological applications in sensing, spectroscopy, imaging, communication [9, 10], 

optoelectronic devices[11], light emitters[12] and solar cells[13]. These properties are attributed to the Ge-NCs $Q C E$, much stronger than in the case of $\mathrm{Si}$ or to interface carrier traps between Ge-NCs and the surrounding $\mathrm{SiO}_{2}$ matrix $[14,15,16,17]$. As a comparison, it has been demonstrated that photo-sensitive structures based on silicon nanocrystallites (Si-nps) can achieve peak responsivity in the range of $0.4 \mathrm{AW}^{-1}-2.8$ $\mathrm{AW}^{-1}$, and optoelectronic conversion efficiency as high as $200 \%$ [18] whereas Ge-NCsbased photo-sensitive devices are even more promising, as the maximum responsivity reported so far is $1.8 \mathrm{AW}^{-1}$ at $-2 \mathrm{~V}$ and about $4 \mathrm{AW}^{-1}$ at $-10 \mathrm{~V}$, respectively. The resulting optoelectronic conversion efficiency was $300 \%$ obtained at $-2 \mathrm{~V}$ bias and 700 $\%$ at $-10 \mathrm{~V}$, respectively[8]. The properties of Ge-NCs incorporated into $\mathrm{SiO}_{2}$ matrix can be strongly influenced by difficulties related to the control of the technological parameters of the deposition and/or to the inevitable formation of defects regardless of the preparation method (sputtering[19], implantation[20] or epitaxial[21]). Structuring of Ge-NCs embedded into $\mathrm{SiO}_{2}$ has been achieved so far by thermal annealing after deposition of $\mathrm{Ge} / \mathrm{SiO}_{2}$ thin layers, or by thermal oxidation of SiGe layers, at high temperature, in excess of $700{ }^{\circ} \mathrm{C}[22,23]$. This range of temperature is lower than the temperature needed to obtain Si-nps (typically around $1100{ }^{\circ} \mathrm{C}$ ), but it is still too high to be appropriate for processing structures and devices on flexible or glass substrates. This is the present challenge to be solved in order to benefit from the advantages in terms of reducing manufacturing cost and much broader range of applications [24, 25].

It is crucial to significantly lower the temperature for structuring Ge-NCs into $\mathrm{SiO}_{2}$ matrix in order to use these materials in Si-based optoelectronics on a chip, where low processing temperature is needed to preserve the functionality of the adjacent $\mathrm{Si}$ electronics[26]. There have been attempts to structure Ge-NCs at temperatures below $400{ }^{\circ} \mathrm{C}$, but the technological methods employed (ultra-high vacuum chemical vapor deposition or wet chemical synthesis) are either too expensive and/or incompatible with the current highly developed silicon technology[27, 28]. The reported attempts using thin films grown by magnetron sputtering for structuring embedded Ge-NCs by postdeposition thermal annealing at $400{ }^{\circ} \mathrm{C}$ show that the obtained Ge-NCs are amorphous and the photo-response properties are weak[8].

In this work an innovative procedure is reported. It was developed to perform the synthesis of Ge-NCs in $\mathrm{SiO}_{2}$ layer during deposition, by heating the substrate at $400{ }^{\circ} \mathrm{C}$ (a temperature higher than the one specific to the deposition process). This is much lower than the temperature needed for structuring the Ge-NCs by postdeposition thermal annealing. We proved the feasibility of the fabrication procedure through an $\mathrm{Al} / \mathrm{Si}-\mathrm{n} / \mathrm{Ge}-\mathrm{NCs}: \mathrm{SiO}_{2} / \mathrm{ITO}$ photo-sensitive structure obtained by magnetron sputtering method while heating the substrate. These structures tested at room temperature exhibit superior performances like great responsivity, quick response and high optoelectrical conversion efficiency upon broadband, from about $450 \mathrm{~nm}$ to approximate $1300 \mathrm{~nm}$, with peak value reaching $850 \%$ at $-1 \mathrm{~V}$ applied bias and about $1000 \mathrm{~nm}$. Optoelectronic devices fabricated by our approach can lead to optimized design strategies for infrared absorbers that can be used in Si-based multi-junction solar 
Photo-sensitive Ge nanocrystal based films controlled by substrate deposition temperature4 cells, for faster and highly photo-sensitive devices based on Ge-NCs or to integrated optoelectronics on Si or flexible substrates.

\section{Experimental}

\subsection{Materials and methods}

$\mathrm{SiGeO}_{2}$ thin films containing Ge-NCs were fabricated on clean $10 \mathrm{~mm} \times 10 \mathrm{~mm}$, ntype (100) Si substrates, with bulk resistivity in the range $10 \Omega \mathrm{cm}-20 \Omega \mathrm{cm}$, by magnetron sputtering depositing, at the same time, $\mathrm{SiO}_{2}$ and Ge from separate three inches sputtering targets (Gamma1000 tool from Surrey Nanosystems). The Si pieces used as substrates were degassed for 5 minutes in vacuum at $200^{\circ} \mathrm{C}$. Deposition chamber was evacuated down to $1 \times 10^{-7}$ Torr before deposition. To achieve targeted 50:50 concentration ratio of $\mathrm{Ge}$ into $\mathrm{SiO}_{2}$ during deposition, technological parameters like direct current $(\mathrm{DC})$ or radio frequency $(\mathrm{RF})$ power, argon gas pressure, and substrate temperature were finely tuned to optimized values of $30 \mathrm{~W} \mathrm{DC,} 262 \mathrm{~W} \mathrm{RF}, 4$ mTorr and $400{ }^{\circ} \mathrm{C}$, respectively. Substrate rotation contributed to the superior quality of the layer (about $250 \mathrm{~nm}$ ) and a good Ge distribution into $\mathrm{SiO}_{2}$.

Electrical and photoelectrical measurements at room temperature were performed on $\mathrm{Al} / \mathrm{Si}-\mathrm{n} / \mathrm{Ge}-\mathrm{NCs}: \mathrm{SiO}_{2} / \mathrm{ITO}$ structures after the $\mathrm{Al}$ back electrode and IndiumTin-Oxide (ITO) matrix top electrodes $\left(3 \times 3 \mathrm{~mm}^{2}\right)$ were deposited by e-beam evaporation (Bestec) and magnetron sputtering (Varian ER3119), respectively, using shadow masking.

\subsection{Characterization}

The structure investigations on $\mathrm{GeSiO}_{2}$ layers were performed by X-ray diffraction (AXS-BRUKER, $\mathrm{CuK}_{\alpha 1}$ with $\lambda=0.15406 \mathrm{~nm}$ ), SPECS X-ray Photoelectron Spectroscopy (XPS) with an analyzer (PHOIBOS 150) and transmission electron microscopy (TEM) using analytical atomic microscope (JEOL, JEM ARM 200F).

Electrical studies were performed on a setup which contains a cryostat provided with optical windows (CCS450 from Janis), a Keithley electrometer (6517A) and a 331 LakeShore controller for temperature. The evaluation of the photo-response properties of the investigated layers was done using three light sources in the measurements: a Xe lamp (450 W) combined with a $1 / 4$ Newport monochromator to provide a monochromatic beam between $200 \mathrm{~nm}-2500 \mathrm{~nm}$, a tungsten-halogen lamp (20 W, Newport) and a laser diode as a more powerful laser source in the NIR domain at $808.5 \mathrm{~nm}$. The reflectance spectra have been taken at a fixed angle of incidence $\left(6^{\circ}\right)$ using a double beam spectrophotometer $(0.25 \mu \mathrm{m}-3 \mu \mathrm{m}, 950$ Perkin Elmer $)$ with specular reflectance fixture (B 0086703). The operation speed investigations of the photo-sensitive structure were evaluated using a mechanical modulator (SR 540) and an oscilloscope (500 MHz WaveJet) together with a standard commercial detector (PDA10CS EC). 


\section{Results and discussions}

In this section, the results of structural investigations, electrical characterization, photoelectrical and response time properties of the $\mathrm{SiO}_{2}$ thin films formed with embedded Ge-NCs and the obtained optical sensitivity of the structure are presented and discussed. To reveal the crucial contribution of Ge-NCs, two types of structures were realized: $(i)$ single thin layer of $\mathrm{Al} / \mathrm{Si}-\mathrm{n} / \mathrm{Ge}-\mathrm{NCs}: \mathrm{SiO}_{2} / \mathrm{ITO}$ test structure and $(i i)$ a similar reference structure $\mathrm{Al} / \mathrm{Si}-\mathrm{n} / \mathrm{SiO}_{2} / \mathrm{ITO}$, with no Ge added.
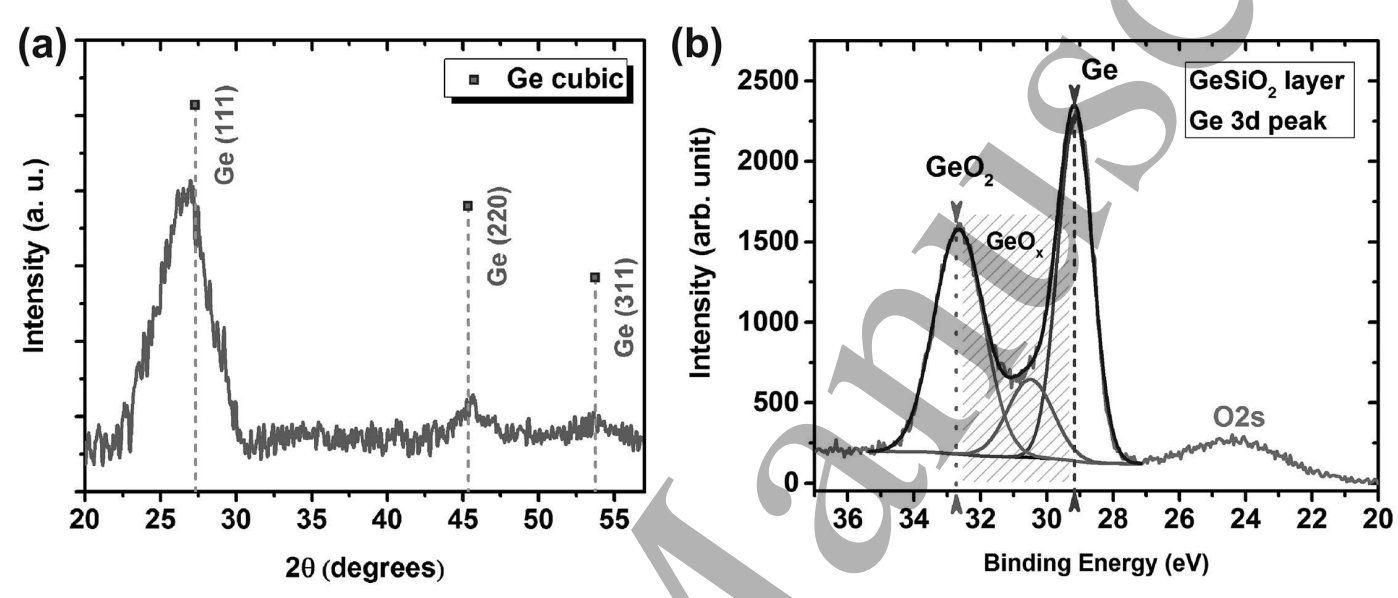

Figure 1. $\mathrm{GeSiO}_{2}$ thin film containing Ge-NCs structured in-situ during deposition of Ge and $\mathrm{SiO}_{2}$ on a Si substrate heated at $400{ }^{\circ} \mathrm{C}$ : (a) X-ray diffractogram and (b) XPS spectra of the Ge3d level pointing the oxidation states of Ge existent in the $\mathrm{GeSiO}_{2}$ layer.

Diffraction spectrum measured on one of the Ge-NCs: $\mathrm{SiO}_{2}$ layer deposited on $\mathrm{Si}$ substrate heated at $400{ }^{\circ} \mathrm{C}$ during deposition is presented in Figure 1(a), which includes the standard X-ray diffraction (XRD) tabulated pattern (Inorganic Crystal Structure Database - ICSD:79-0001) of Ge cubic. The plotted diffractogram shows maxima corresponding to (111), (220) and (311) Ge cubic structure. It can be observed that diffraction peaks are broad, indicating the presence of small nanocrystals, of about 4.5 $\mathrm{nm}$ as estimated using Scherrer equation. Figure 1(b) present the XPS spectra of the $\mathrm{Ge} 3 \mathrm{~d}$ core levels. The spectra suggest that the investigated films contain $\mathrm{GeO}_{2}$ and $\mathrm{GeO}_{x}$ subspecies of Ge.

The high resolution (HR)TEM picture of the cross section (XTEM) specimen (Figure 2 (a) ) shows in detail the interface between $\mathrm{Si}$ substrate, native $\mathrm{SiO}_{2}$ film and the deposited Ge-NCs:SiO 2 layer. Segregation of Ge nanoparticles forms a band at the interface between native $\mathrm{SiO}_{2}$ and $\mathrm{Ge}-\mathrm{NCs}: \mathrm{SiO}_{2}$ film, as a result of deposition conditions. EDX spectrum (inset Figure 2 (a)) recorded on Ge-NCs: $\mathrm{SiO}_{2}$ film demonstrates that $\mathrm{Si}$ and $\mathrm{Ge}$ were deposited in equal atomic concentration. The HRTEM image of GeNCs: $\mathrm{SiO}_{2}$ film presents the distribution of Ge-NCs $(\sim 5 \mathrm{~nm})$ in the amorphous $\mathrm{SiO}_{2}$ (Figure 2(b)). The inset shows an oriented Ge-NC. The microscopy results confirm the crystallinity of the Ge grains, previously suggested by XRD. 
Photo-sensitive Ge nanocrystal based films controlled by substrate deposition temperature6

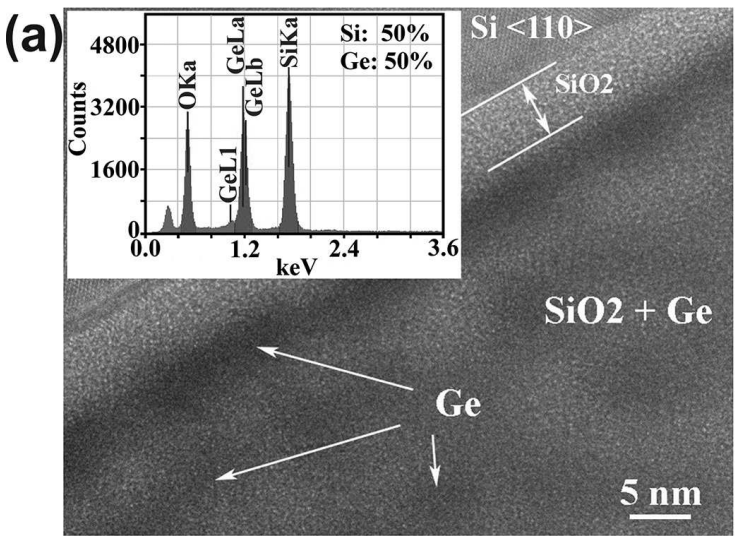

(b)

Figure 2. HRTEM pictures: (a) Ge-NCs: $\mathrm{SiO}_{2} /$ native $\mathrm{SiO}_{2} / \mathrm{Si}$ interface with EDX spectra (inset); (b) spatial distribution of Ge-NCs within the $\mathrm{SiO}_{2}$ layer with an oriented Ge-NC (inset).

Figure 3(a) shows a drawing of the investigated structure. Figure 3(b) shows the schematic representation of the electrical transport mechanism in the $\mathrm{Al} / \mathrm{Si}-\mathrm{n} / \mathrm{Ge}-$ $\mathrm{NCs}: \mathrm{SiO}_{2} / \mathrm{ITO}$ system. The electrons are tunneling from the upper contact (ITO) to the Ge-NCs incorporated into the $\mathrm{SiO}_{2}$ film and they move inside the active Ge$\mathrm{NCs}: \mathrm{SiO}_{2}$ layer percolating between neighboring Ge-NCs[29]. The active area of the photo-sensitive structure is $9 \mathrm{~mm}^{2}$. The results of "on/off" measurements, which reveal the photovoltaic behavior of the structure, are represented in Figure 3(c). The two characteristics are recorded at two different values of the incident optical power $\left(P_{\text {opt }}\right.$ - the optical power incident on the active zone of the structure), respectively $5 \mathrm{~mW}$ and $20 \mathrm{~mW}$. These measurements were performed under a continuous illumination using an incandescent lamp $(20 \mathrm{~W}$, tungsten-halogen $)$. The $P_{\text {opt }}$ was measured using a neutral power meter (LaserStar). The resulting open-circuit voltage has values between $120 \mathrm{mV}$ and $150 \mathrm{mV}$ depending on the applied optical power, which emphasizes the great optical sensitivity of the investigated structures, proving their suitability for optoelectronic applications. It is known that a structure with photo-voltaic properties can work without external bias applied. Such a self-powering photo-sensitive device is a promising nominee for developing new devices with high sensitivity at reduced scale, hence low cost.

In Figure 3(d) current - voltage $(I-V)$ characteristics obtained in dark, under illumination using a tungsten-halogen lamp $\left(P_{\text {opt }}=20 \mathrm{~mW}\right)$ and respectively continuous illumination at different monochromatic wavelengths is plotted. The dark current level is slightly higher than expected for Ge-NCs incorporated in a stoichiometric $\mathrm{SiO}_{2}$ matrix and this can be related to $\mathrm{SiO}_{2}$ deviation from stoichiometry and chemical reduction of $\mathrm{GeO}_{x}$ (presented in Figure 1(b)), which is the major mechanism for controlling the size of Ge-NCs. It is known that, even slight deviations from stoichiometry can create defects into the matrix, which are favorable for photovoltaic applications in the case of $\mathrm{GeSiO}_{x}$ films with a low oxygen deficiency $(\mathrm{x}<2)[30,31]$.

For the investigated structures, the voltage onto ITO contact has been applied in 
(a)

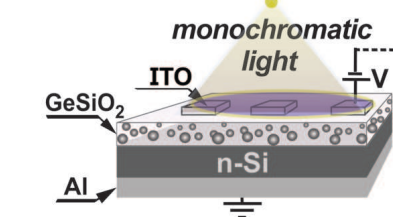

(b)
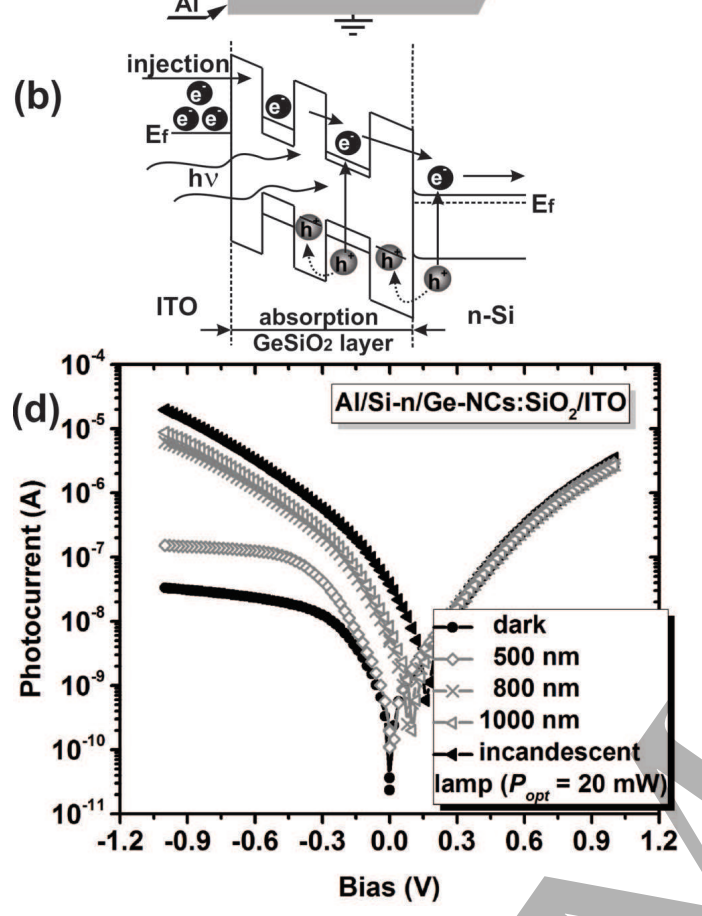
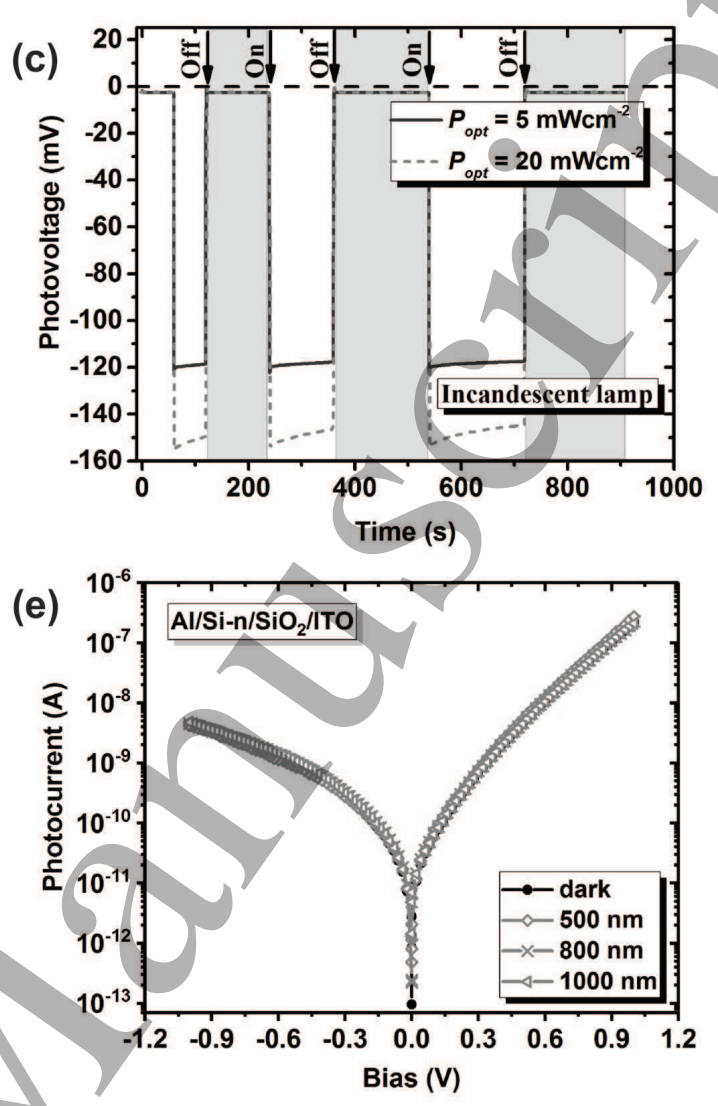

Figure 3. Electrical characterization: (a) schematic representation of the photosensitive test structure and measurement geometry; (b) transport mechanism schematic representation of the photoresponse; $(c)$ photovoltage measurements performed at $P_{\text {opt }}$ of $5 \mathrm{~mW}$ and $20 \mathrm{~mW}$ respectively, on a capacitor-like photo-sensitive structure (Al/Si-n/Ge-NCs:SiO $2 / \mathrm{ITO}) ;(d) I-V$ curves of a photo-sensitive structure with Ge-NCs; $(e) I-V$ curves of the similar structure without Ge incorporated into the $\mathrm{SiO}_{2}$ layer. The characteristics plotted in Figure3 $(d)$ and $(e)$ were obtained for photo-sensitive structure in the dark, under illumination with incandescent lamp ( $P_{\text {opt }}$ $=20 \mathrm{~mW})$ and monochromatic illumination $(500,800$ and $1000 \mathrm{~nm})$, respectively.

the range $-1 \mathrm{~V}-1 \mathrm{~V}$ (in steps of $20 \mathrm{mV}$ ) and the silicon substrate was earthed. For such structures, the bias voltage splits across a few junctions, as the interface formed between ITO top electrode and Ge-NCs:SiO 2 layer, active layer (Ge-NCs:SiO ${ }_{2}$ ) zone or those located at the Ge-NCs:SiO $/$ native oxide/Si interface[20]. According to the studies leaded by P. Castrucci et. al., the native $\mathrm{SiO}_{2}$ separation zone observed from microstructure investigations is formed at the $\mathrm{Si} / \mathrm{Ge}-\mathrm{NCs}: \mathrm{SiO}_{2}$ interface and it acts like a junction generating a relative inflexion of $\mathrm{Si}$ and $\mathrm{Ge}$ conduction and valence bands (Ge-NCs continuous layer) that makes a depletion layer into the Si substrate[32]. Characteristics performed in the dark, at $\pm 1 \mathrm{~V}$ bias voltage, exhibit low currents and a rectifying behavior of about $10^{2}$ ratio between positive and negative sides. The unidirectional behavior (rectifying) may be the result of the complex junctions present 
in the investigated structures which operate as a rectifying diode-like contacts. The characteristics are almost unchanged under illumination (continuous illumination with an incandescent lamp) at forward bias, but a significant rise of current of about $10^{3}$ times is observed under reverse bias thanks to electron-hole couple photo-generated in the Ge-NCs and Si-n substrate. In this case, both electrons and holes move percolating through the Ge-NCs network. Thus, a dynamically trapped positive charge is produced improving the electron injection and hence growing the rate of process and directing to a sharp increase of photoresponse also due to barrier lowering under illumination. The active layer (Ge-NCs:SiO ${ }_{2}$ ) acts as a network of resistors in which every Ge-NC is tied with its Ge-NCs neighbors through a finite tunneling resistor. So, the charge careers from Ge-NCs would pass by tunneling towards their neighboring Ge-NCs choosing the path with the smallest resistance. An analogous mechanism was proposed by B. C. Hsu et. al.[33]. The photo-response properties of the structure are directly associated with generating mechanism and to collecting of electron and hole as pairs. To emphasize the role played by the Ge-NCs within the structure, we also fabricated a reference structure $\left(\mathrm{Al} / \mathrm{Si} / \mathrm{SiO}_{2} / \mathrm{ITO}\right)$ where the total $\mathrm{SiO}_{2}$ film thickness is the same as the $\mathrm{GeSiO}_{2}$ layer from test structure, but no Ge was embedded.

Characteristics obtained on the reférence structure are presented in Figure 3(e). The dark current is much smaller $\left(-4.2 \times 10^{-9} \mathrm{~A}\right.$ at $\left.-1 \mathrm{~V}\right)$ under reverse-bias compared to the photo-sensitive test structure that contain Ge-NCs $\left(-3.3 \times 10^{-8} \mathrm{~A}\right.$ at $\left.-1 \mathrm{~V}\right)$, because the carrier tunneling rate through the $\mathrm{SiO}_{2}$ dielectric is much lower. The absence of GeNCs leaves the structure insensitive to light, proving the key role played by the Ge-NCs on radiation sensing properties of the structure.

The experimental setup for studying the wavelength dependence of responsivity $\left(R_{s}\right)$ is represented in Figure 4(a). The calculated $R_{s}$, plotted in Figure 4(b), as the ratio of the photocurrent generated in the structure and the optical power incident on the investigated zone for different values of reverse bias $(-0.1 \mathrm{~V},-0.5 \mathrm{~V}$ and $-1 \mathrm{~V}$ respectively), were obtained using the following equation[34]:

$$
R_{s}=\frac{I_{\text {photo }}(\lambda)}{P_{o p t}(\lambda)}
$$

where $I_{\text {photo }}$ is the current obtained from the structure under illumination. $P_{\text {opt }}$ was determined using a powermeter (Ophir by LaserStar) equipped with a 3A-P-SH$\mathrm{V} 1$ sensor. The photo-sensitivity of the structure under $-1 \mathrm{~V}$ bias exceeds $5 \mathrm{AW}^{-1}$ at a wavelength of about $1000 \mathrm{~nm}$. Increasing the density of Ge-NCs into $\mathrm{SiO}_{2}$ or by optimizing the Ge-NCs size represent the main possible ways that can lead to widen the high responsivity spectral range. The responsivity characteristics do not account for the light reflected from the structure, and consequently one cannot make a clear correlation between the photogeneration of carriers and contribution of physics phenomena involved. The reflectance spectra for Ge-NCs: $\mathrm{SiO}_{2}$ thin film deposited in-situ at $400{ }^{\circ} \mathrm{C}$ on $\mathrm{Si}$ substrate is presented in Figure 4(c), right axis. Figure 4(c) left axis shows the obtained 
1

2

3

4

5

6

7

8

9

10

Photo-sensitive Ge nanocrystal based films controlled by substrate deposition temperature9

(a)

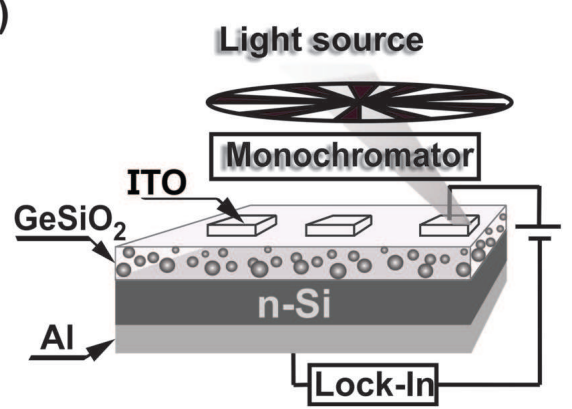

(c)

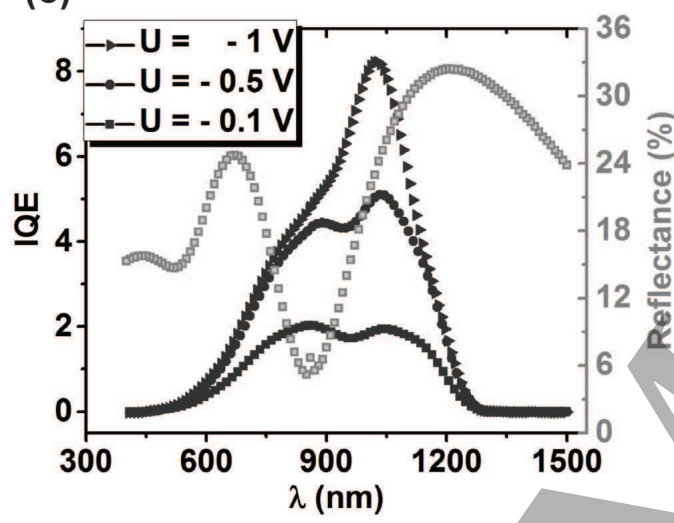

(b)

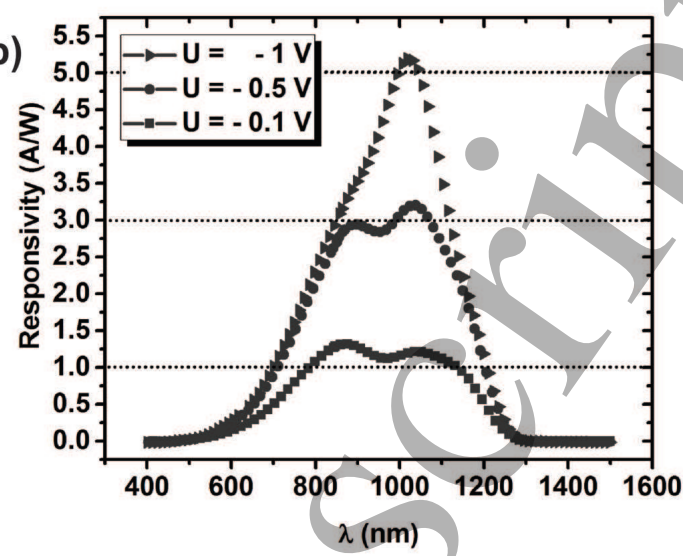

(d)

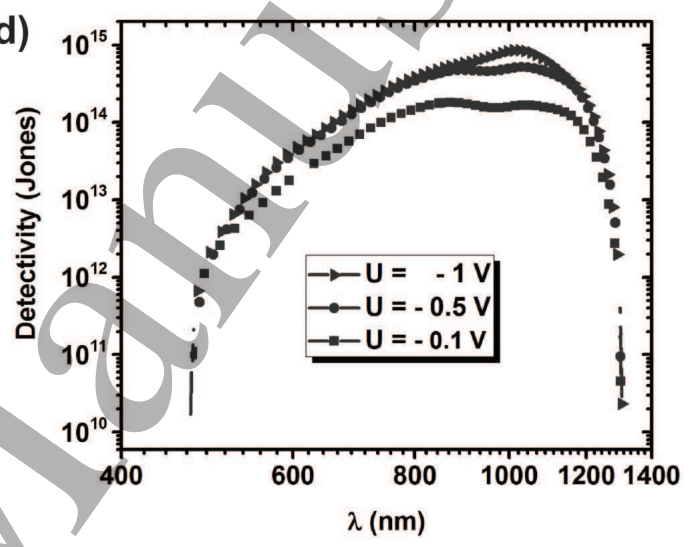

Figure 4. Spectral photosensitivity of $\mathrm{Al} / \mathrm{Si}-\mathrm{n} / \mathrm{Ge}-\mathrm{NCs}: \mathrm{SiO}_{2} / \mathrm{ITO}$ structure biased at $-0.1 \mathrm{~V},-0.5 \mathrm{~V}$ and $-1.0 \mathrm{~V} ;(a)$ schematic of the measurement setup; (b) spectral responsivity; (c) internal quantum efficiency $(I Q E)$ of the photo-sensitive structure (left axis) and reflectance (right axis); $(d)$ specific detectivity.

$I Q E$ for several values of the reverse bias and it was calculated using the equation:

$$
I Q E=\frac{h c I_{\text {photo }}(\lambda)}{q \lambda(1-R) P_{o p t}(\lambda)}
$$

where $R$ is the reflectance, $\lambda$ the wavelength, $\mathrm{q}$ is the elementary charge, $\mathrm{h}$ is Planck constant and $\mathrm{c}$ is the speed of light in vacuum. At wavelength $\lambda \sim 1000 \mathrm{~nm}$ and applied bias of $-1 \mathrm{~V}$, the photo-sensitive test structure shows $I Q E$ as high as $850 \%$. This value of $I Q E$ is the highest reported so far in the scientific literature for this type of structures, and it was previously predicted by the latest analysis reported by S. Saeed et. al.[35] which demonstrated the multiplication process of charge carriers in Ge-NCs. The high $I Q E$ value suggests that about eight charge carriers can be generated for each incident photon absorbed under illumination with a wavelength around $1000 \mathrm{~nm}$. This can be interpreted as being the result of preferential trapping of holes (generated under illumination) in the Ge-NCs: $\mathrm{SiO}_{2}$ active layer, which causes an enhancement in the flow of electrons from ITO top electrode, to maintain charge neutrality within the film. The obtained responsivity suggests that high values of photocurrent can be achieved 
under a relatively small optical illumination. To evidence the test structure sensitivity, the detectivity $\left(D^{*}\right)$ was determined, as being directly related to the capability of a device to sense weak optical signals. To fabricate photo-sensitive devices with high detectivity, it is necessary the structure have high responsivity and lowest possible dark current. Figure 4(d) shows the spectral detectivity of the photo-sensitive test structure, calculated using the following expression[34]:

$$
D^{*}=\frac{A^{1 / 2} R_{s}}{\left(2 q I_{\text {dark }}\right)^{1 / 2}}=\frac{R_{s}}{\left(2 q J_{\text {dark }}\right)^{1 / 2}}
$$

in which $\mathrm{A}$ is the structure area under investigation, q represents the elementary charge, $I_{d a r k}$ and $J_{d a r k}$ are the dark current and the dark current density, respectively.
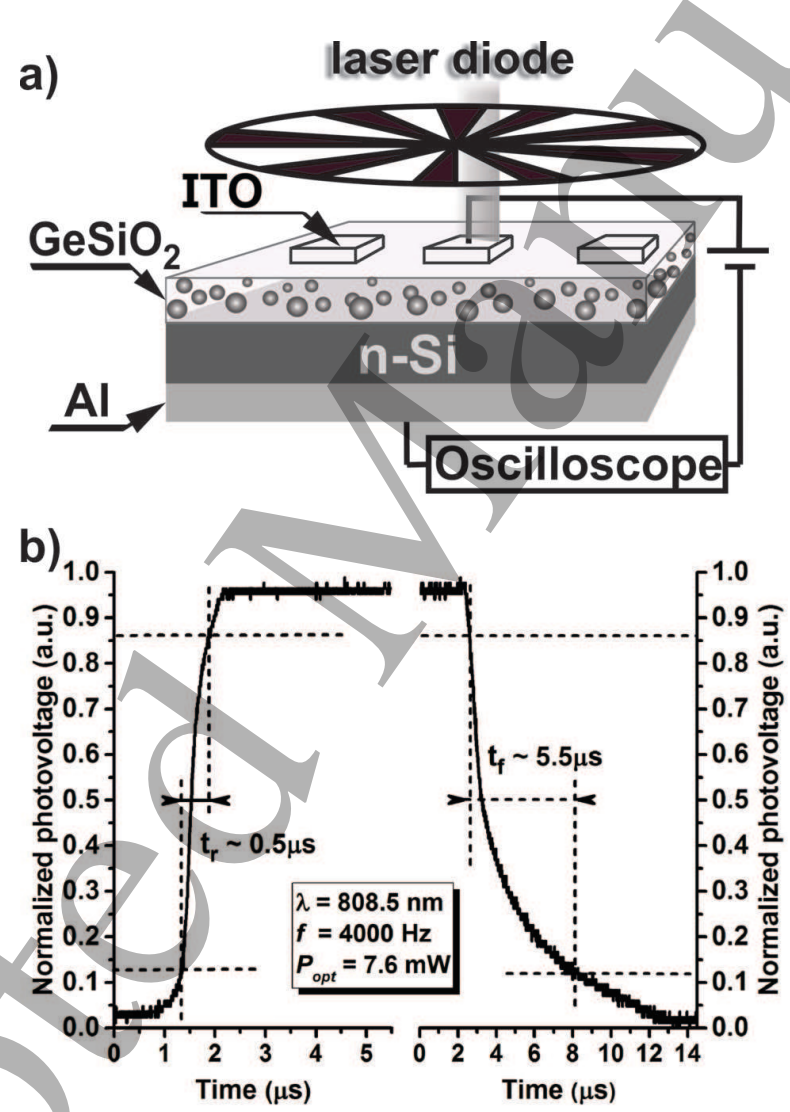

Figure 5. Response speed of the photo-sensitive unbiased structure under $808.5 \mathrm{~nm}$ laser beam illumination, $P_{\text {opt }}=7.6 \mathrm{~mW}:(a)$ schematic of the measurement setup; $(b)$ rise front (left axis) and falling edges (right) at $f=4 \mathrm{kHz}$.

To estimate the detectivity, it is accepted that current measured in dark conditions is dominated by the shot noise[34, 36]. Al/Si-n/Ge-NCs:SiO $2 /$ ITO photo-sensitive structure presents high specific detectivity of $10^{14}$ Jones over the wide wavelength interval from approximately $450 \mathrm{~nm}$ to $1300 \mathrm{~nm}$. This high detectivity can be linked to the junction design and the quality of processing. The Ge-NCs size and the relatively high Ge content in the fabricated structure contribute to such extending spectral 


\section{Photo-sensitive Ge nanocrystal based films controlled by substrate deposition temperature11}

sensitivity range as also resulted from the analysis conducted by J. Ni et. al.[37]. The high $R_{s}$ and $D^{*}$ are possible as a result of reduced recombination due to the extended lifetime of the photo-generated carriers. The results reported here for this structure are slightly lower compared with $\mathrm{ZnO}$ nanoparticles based photo-sensitive structure (at 360 $\mathrm{nm}, D^{*}$ is about $3.4 \times 10^{15}$ Jones) [38], but the performance is much better compared with silicon photodiodes $\left(R_{s} \sim 300 \mathrm{AW}^{-1}\right.$ and $D^{*} \sim 10^{13}$ Jones)[39], or photo-sensitive structures based on graphene
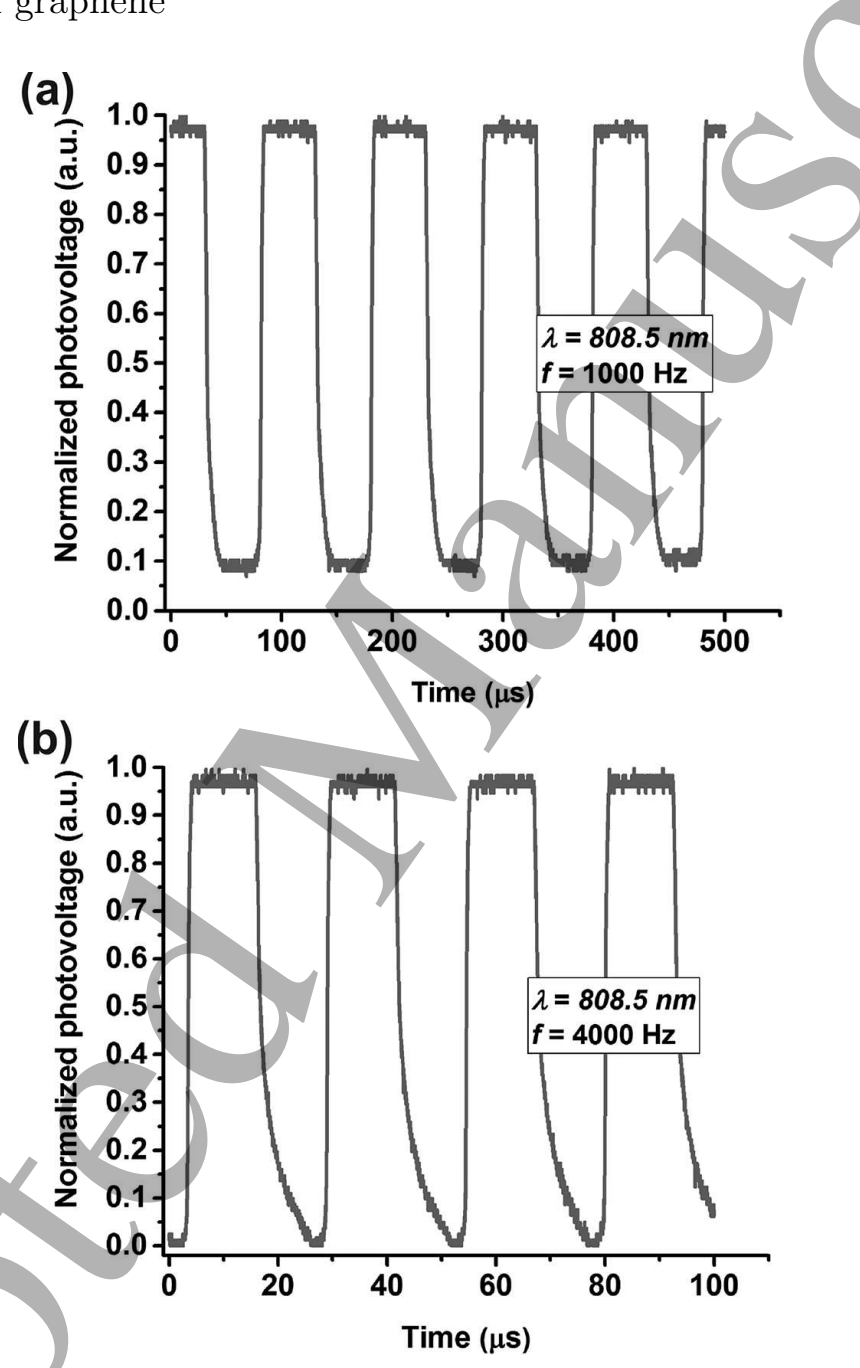

Figure 6. The photo-sensitivity of the self-powering $\mathrm{Al} / \mathrm{Si}-\mathrm{n} / \mathrm{Ge}-\mathrm{NCs}: \mathrm{SiO}_{2} / \mathrm{ITO}$ test structure under modulated NIR light irradiation $\left(808.5 \mathrm{~nm}\right.$ laser, $\left.\mathrm{P}_{\text {opt }}=7.6 \mathrm{~mW}\right)$ at the frequency of $(a) 1000 \mathrm{~Hz}$ and $(b) 4000 \mathrm{~Hz}$, respectively.

$\left(R_{s} \sim 1.0 \times 10^{4} \mathrm{AW}^{-1}\right.$ at $632 \mathrm{~nm}, D^{*} \sim 10^{12}$ Jones $)[40,41]$. The spectral width of $450 \mathrm{~nm}$ to $1300 \mathrm{~nm}$ obtained from spectral investigations is in good agreement with the results reported in the literature[37, 42, 43, 44] and with the results obtained from structural investigations, which reveal the presence of small Ge-NCs $(\sim 5 \mathrm{~nm})$.

The experimental setup for photo-sensitive response speed is presented in Figure 
5(a). The photo-sensitive structure response speed is also a key parameter for developing high-speed photo-sensitive devices for applications in optical communication, imaging, and so on. The response speed results are reported in Figure 5(b). To record the response speed of the structure, the photovoltage signal was read using an oscilloscope. Without any external bias voltage, the rise time $\left(t_{r}\right)$ estimated from photoresponse curve is about $0.5 \mu \mathrm{s}$ (left axis) and the fall time $\left(t_{f}\right)$ of about $5.5 \mu \mathrm{s}$ (right axis). The $t_{r}$ and $t_{f}$ are defined as the time interval in which the photo-response increase, respéctively decrease, between $10 \%$ to $90 \%$ of its maximum value.

The characteristics presented in Figure 6(a) and Figure 6(b), show that photo-sensitivity of the self-powering $\mathrm{Al} / \mathrm{Si}-\mathrm{n} / \mathrm{Ge}-\mathrm{NCs}: \mathrm{SiO}_{2} /$ ITO test structure under modulated NIR light irradiation $(808.5 \mathrm{~nm}$, laser diode) has a very fast response at frequencies between $1000 \mathrm{~Hz}$ and $4000 \mathrm{~Hz}$. An optical chopper was used to modulate the laser beam.

To further improve the properties, special attention must be paid to optimization of surface/interface and Ge-NCs crystalline quality and $\mathrm{SiO}_{2}$ thin film by optimizing growth parameters to reduce carrier recombination. More, reducing the device area will further improve the response speed. The reported results clearly describe the important role of Ge-NCs in the heterojunction/structure for improving the photoresponse properties. As nowadays devices face the challenge of sensing light in a broad wavelength range, for industrial and scientific applications, the obtained results, reported in this work, emphasize a real potential advantage for solar cells based on $\mathrm{Si}$ multi-junction with enlarged spectral sensitivities into NIR.

\section{Conclusions}

In conclusion, we developed a procedure to perform in-situ synthesis of Ge-NCs embedded into $\mathrm{SiO}_{2}$ matrix during deposition, by heating the substrate at $400{ }^{\circ} \mathrm{C}$, a temperature higher than the one corresponding to deposition, but much lower than temperature necessary for post-deposition thermal treatment, as employed so far. We proved the feasibility of the procedure through a Al/Si-n/Ge-NCs:SiO $/$ ITO photo-sensitive structure fabricated by magnetron sputtering and by investigating its structural, electric and photoelectric properties and photoresponse in a broad wavelength range. The test photo-sensitive structure, operating at room temperature, exhibits, at only $-1 \mathrm{~V}$ bias, very fast response of $0.5 \mu \mathrm{s}$, the high responsivity of $5 \mathrm{AW}^{-1}$, photo-detectivity higher than $10^{14}$ Jones with broad spectral response from $450 \mathrm{~nm}$ to $1300 \mathrm{~nm}$ and great optoelectronic conversion efficiency with peak value reaching $850 \%$. We attribute these properties to the increased photoconductivity originating from the holes trapped in the Ge-NCs. The procedure described here indicates a further direction for developing optimized devices with broad spectral sensitivities in NIR, based on the role of Ge-NCs within the structures fabricated at lower temperature, providing also a new route to developing technologies for light harvesting devices, solar cells or hybrid hetérojunctions on flexible substrates and/or in Si-based optoelectronic integration. 
Photo-sensitive Ge nanocrystal based films controlled by substrate deposition temperature13

\section{Acknowledgments}

This work was supported by the Romanian National Authority for Scientific Research through the Core Program, Project PN09-450101 and CNCS-UEFISCDI Contracts PNII-PT-PCCA-9/2012, PNII-ID/289-2011 and M-ERA.NET Project number 33/2016.

\section{References}

[1] Guichard RA, Barsic ND, Sharma S, Kamins IT and Brongersma LM 2006 Nano Lett. 6(9) $2140-2144$

[2] Huang J, Chim KW, Wang S, Chiam YS and Wong ML 2009 Nano Lett. 9(2) 583-589

[3] Ray KS, Maikap S, Banerjee W and Das S. 2013 J. Phys. D: Appl. Phys. 46(15) 153001

[4] Shklyaev AA, Romanyuk NK and Latyshev VA 2013 Journal of Surface Engineered Materials and Advanced Technology 3(3) 195-204

[5] Cosentino S, Barbagiovanni GE, Crupi I, Miritello M, Nicotra G, Spinella C, Pacifici D, Mirabella S and Terrasi A 2015 Solar Energy Materials \& Solar Cells 135 22-28

[6] Ma Z, Kuhn M and Johnson CD 2017 Semicond. Sci. Technol. 32030201

[7] de los Santos Valladares L, Bustamante Dominguez A, Ionescu A, Brown A, Sepe V, Steiner U, Avalos Quispe O, Holmes S, Majima Y, Langford R and Barnes WHC 2016 Semicond. Sci. Technol. 31125017

[8] Cosentino S, Liu Pei, Le TSon, Lee S, Paine D, Zaslavsky A, Pacifici D, Mirabella S, Miritello M, Crupi I and Terrasi A 2011 Appl. Phys. Lett. 98221107

[9] Rogalski A 2003 Prog. Quant. Electron. 27(2-3) 59-210

[10] Clark J and Lanzani G 2010 Nature Photon. 4 438-446

[11] Liu X, Ji X, Liu M, Liu N, Tao Z, Dai Q, Wei L, Li C, Zhang X and Wang B. 2015 ACS Appl. Mater. Interfaces 7(4) 2452-2458

[12] Jain RJ, Hryciw A, Baer MT, Miller BAD, Brongersma LM and Howe TR 2012 Nature Photonics $6398-405$

[13] Kechiantz MA, Kocharyan ML and Kechiyants MH 2007 Nanotechnology 18405401

[14] Tzeng SS and Li WP 2008 Nanotechnology 19(23) 235203

[15] Chien YC, Lai TW, Chang JY, Wang CC, Kuo HM and Li WP 2014 Nanoscale 6 5303-5308

[16] Lepadatu MA, Stavarache I, Ciurea LM and Iancu V 2010 J. Appl. Phys. 107033721

[17] Ciurea LM and Lepadatu MA 2015 Dig. J. Nanomater. Bios. 10(1) 59-87

[18] Shieh -MJ, Yu -CW, Huang YJ, Wang -KC, Dai -TB, Jhan -YH, Hsu -WC, Kuo -CH, Yang -LF and Pan -LC 2009 Appl. Phys. Lett. 94241108

[19] Wolf O, Balberg I and Millo O 2015 Thin Solid Films 574 184-188

[20] Zhang-YJ, Ye-HY and Tan -LX 1999 Appl. Phys. Lett. 74 2459-2461

[21] Masini G, Cencelli V, Colace L, De Notaristefani F and Assanto G. 2003 Physica E 16(3-4) $614-619$

[22] Ortiz IM, Rodrguez A, Sangrador J, Rodrguez T, Avella M, Jimnez J and Ballesteros C 2005 Nanotechnology 16(5) S197-S201

[23] Zhang B, Shrestha S, Aliberti P, Green AM and Conibeer G Synthesis and structural properties of Ge nanocrystals in multilayer superlattice structure. In Nanoscale Photonic and Cell Technologies for Photovoltaics II, Vol. 7411 (Ed: L. Tsakalakos), Proc. SPIE 7411, San Diego, CA 2009, 741103.

[24] Zacharias M, Heitmann J, Scholz R, Kahler U, Schmidt M and Blasing J 2002 Appl. Phys. Lett. $80661-663$

[25] Conibeer G, Green M, Cho -CE, Knig D, Cho -HY, Fangsuwannarak T, Scardera G, Pink E, Huang Y, Puzzer T, Huang S, Song D, Flynn C, Park S, Hao X and Mansfield D 2008 Thin Solid Films 516(20) 6748-6756 
Photo-sensitive Ge nanocrystal based films controlled by substrate deposition temperature14

[26] Schmitz J, Rangarajan B and Kovalgin A 2015 Solid State Electron. 108 8-12

[27] McComber AK, Duan X, Liu J, Michel J and Kimerling CL 2012 Adv. Funct. Mater. 22(5) 10491057

[28] Lu X, Korgel AB and Johnston PK 2005 Chem. Mater. 17(25) 6479-6485

[29] Stavarache I, Lepadatu MA, Maraloiu VA, Teodorescu SV and Ciurea LM 2012 J. Nanopart. Res. 14930

[30] Nyrow A, Sternemann C, Sahle JCh, Hohl A, Zschintzsch-Dias M, Schwamberger A, Mende K, Brinkmann I, Moretti Sala M, Wagner R, Meier A, Vlklein F and Tolan M 2013 Nanotechnology 24(16) 165701

[31] Groiss H, Spindlberger L, Oberhumer P, Schffler F, Fromherz T, Grydlik M and Brehm M 2017 Semicond. Sci. Technol. 32 02LT01

[32] Castrucci P, Del Gobbo S, Speiser E, Scarselli M, De Crescenzi M, Amiard G, Ronda A and Berbezier I 2010 J. Non-Cryst. Solids 356(37-40) 1940-1942

[33] Hsu -CB, Chang TS, Shie-RC, Lai -CC, Chen SP and Liu WC 2003 IEEE Electron Device Lett. 24(5) $318-320$

[34] Choi W, Cho YM, Konar A, Lee HJ, Cha -BG, Hong CS, Kim S, Kim J, Jena D, Joo J and Kim S Adv. Mater. 24(43) 5832-5836

[35] Saeed S, de Weerd C, Stallinga P, Spoor MCF, Houtepen JA, Siebbeles ADL and Gregorkiewicz T 2015 Light Sci. Appl. 4 e251

[36] Jha AR 2000 Applications to electro-optics, photonic devices, and sensors In Infrared Technology, Wiley Series in Microwave and Optical Engineering, Chang K., Ed.; New York 2000.

[37] Ni J, Liu Q, Zhang JJ, Ma J, Wang H, Zhang DX and Zhao Y 2014 Solar Energy Materials \&3 Solar Cells 126 6-10

[38] Guo F, Yang B, Yuan Y, Xiao Z, Dong Q, Bi Y and Huang J 2012 Nat. Nanotechnol. 7 798-802

[39] Guo Y, Yu G and Liu Y. 2010 Adv. Mater. 22(40) 4427-4447

[40] Chen Z, Cheng Z, Wang J, Wan X, Shu C, Tsang KH, Ho PH and Xu -BJ 2015 Adv. Opt. Mat. 3(9) $1207-1214$

[41] Kim OC, Kim S, Shin HD, Kang SS, Kim MJ, Jang WC, Joo SS, Lee SJ, Kim HJ, Choi -HS and Hwang E 2014 Nat. Commun. 53249

[42] Ruddy AD, Johnson CJ, Ryan Smith E and Neale RN 2010 ACS Nano 4(12) 7459-7466

[43] Iancu V, Mitroi RM, Lepadatu MA, Stavarache I and Ciurea LM 2011 J. Nanopart. Res. 13 $1605-1612$

[44] Lai TW and Li WP 2007 Nanotechnology 18(14) 145402 